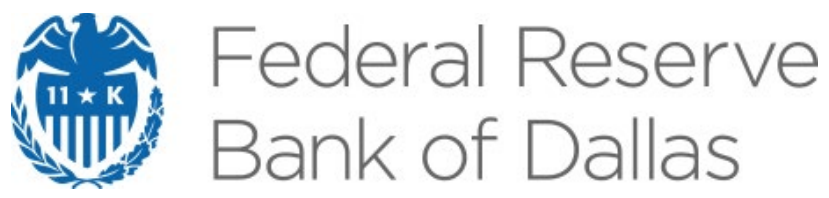

\title{
Imperfect Substitutability in Real Estate Markets and the Effect of Housing Demand on the Macroeconomy
}

J. Scott Davis, Kevin X.D. Huang and Ayse Sapci

Globalization Institute Working Paper 401 September 2020

Research Department

https://doi.org/10.24149/gwp401

Working papers from the Federal Reserve Bank of Dallas are preliminary drafts circulated for professional comment. The views in this paper are those of the authors and do not necessarily reflect the views of the Federal Reserve Bank of Dallas or the Federal Reserve System. Any errors or omissions are the responsibility of the authors. 


\title{
Imperfect Substitutability in Real Estate Markets and the Effect of Housing Demand on the Macroeconomy*
}

\author{
J. Scott Davis ${ }^{\dagger}$ Kevin X.D. Huang ${ }^{\ddagger}$ and Ayse Sapcis
}

September 7, 2020

\begin{abstract}
Changes in housing demand can have a macroeconomic effect through the collateral channel, where the change in residential real estate prices is associated with a change in commercial real estate prices, affecting firm collateral and thus firm investment. We argue that this channel is weaker when residential and commercial real estate are poor substitutes. Using cross-state heterogeneity in the strength of zoning regulations as a proxy for heterogeneity in the substitutability of residential and commercial real estate, we first show with firm level data that the strength of local zoning regulations has a negative effect on the estimated increase in firm investment following an increase in local residential real estate prices. We then construct a DSGE model where land has both residential and commercial uses and estimate it using Bayesian techniques and U.S. macroeconomic data. We find the average elasticity of substitution between commercial and residential real estate in the U.S. to be around 0.35 , but in states with strong zoning restrictions it can be as low as 0.16 and in states with weak zoning restrictions it can be as high as 0.66 . Simulations of the model show how these differences in zoning restrictions can affect the transmission of a housing demand shock to the macroeconomy.
\end{abstract}

JEL Codes: R10; R30; E30

Keywords: Commercial real estate; residential real estate; housing demand shock; zoning

\footnotetext{
*We would like to thank Zheng Liu for many helpful comments and suggestions. We would also like to thank Andrew Johnson for excellent research assistance. The views presented here are those of the authors and do not necessarily represent the views of the Federal Reserve Bank of Dallas or the Federal Reserve System.

${ }^{\dagger}$ Corresponding author: J. Scott Davis, Federal Reserve Bank of Dallas, email: scott.davis@dal.frb.org.

${ }^{\ddagger_{K}}$ Kevin X.D. Huang, Vanderbilt University, email: kevin.huang@vanderbilt.edu.

§Ayse Sapci, Utah State University, email: ayse.sapci@usu.edu.
} 


\section{Introduction}

This paper asks whether increases in residential property prices lead to an increase in business investment through the collateral channel. Liu et al. (2013) (LWZ hereafter) estimate a Bayesian dynamic stochastic general equilibrium (DSGE) model using U.S. aggregate data and argue that a housing demand shock is a major driver of fluctuations in output and investment. Land is used for both housing and an input into production. Land owned by entrepreneurs can serve as collateral, so a positive housing demand shock will push up the price of land, raising the value of collateral for entrepreneurs. ${ }^{1}$ Through this collateral channel, a housing demand shock allows entrepreneurs to increase their borrowing and investment. ${ }^{2}$ Chaney et al. (2012) (CST hereafter) address the same question using different data and a different methodology. Using firm level data and comparing the effect of a change in local real estate prices on the investment rates of local property-owning and non-property owning firms, they argue that an increase in local real estate prices that increases firm collateral by $\$ 1$ leads to a $\$ 0.06$ increase in corporate investment for local firms.

The strength of this collateral channel depends on the substitutability of residential and commercial real estate. For an increase in local residential real estate prices or a housing demand shock to affect the value of a firm's collateral relies on the fact that residential and commercial real estate are substitutable and thus an increase in residential real estate prices is associated with an increase in commercial real estate prices. LWZ model residential and commercial real estate as perfect substitutes. But as we report in the next section, the correlation between aggregate residential and commercial real estate prices in the U.S. is 0.64, and this masks the fact that this correlation is low or even negative in some states like

\footnotetext{
${ }^{1}$ Iacoviello and Neri (2010) show that these housing demand shocks explain a large proportion of the fluctuations in residential real estate prices, and Liu et al. (2019) provide a microfoundation for this housing demand shock through a heterogenous agent model with a credit supply shock.

${ }^{2}$ Guerrieri and Iacoviello (2017) argue that the effect of housing collateral on the tightness of the borrowing constraint is asymmetric and when the constraint is occasionally binding an increase in collateral values has much less effect than a fall in collateral values.
} 
Connecticut and Ohio with strong zoning or land use restrictions while this correlation is close to one in some states like Texas and Oklahoma with weak zoning or land use restrictions. ${ }^{3}$

Using cross-state heterogeneity in the strength of zoning and land use restrictions as a proxy for cross-state heterogeneity in the substitutability of residential and commercial real estate, we ask how the imperfect substitutability between residential and commercial real estate affects the strength of the collateral channel. We go about this in two ways, (1) extending the reduced form empirical approach of CST, and (2) extending of the Bayesian DSGE modelling approach of LWZ.

First, we present a simple extension of the estimation in CST. In CST the variable of interest is the market value of a firm's real estate holdings, and they measure the effect of the value of real estate on the investment rates of local land owning firms. The market value of a firm's real estate is proxied by local residential property prices, and thus the empirical strategy is based on measuring the effect of an increase in local residential real estate prices on the investment rates of local land owning firms.

However, this assumes that any change in residential real estate prices is associated with a similar change in commercial real estate prices and thus the value of a firm's collateral. If residential and commercial real estate are close substitutes this should indeed be the case, but if they are not, the channel from a change in residential property prices to a change in the value of a firm's collateral is weaker. To test this, we simply interact local residential real estate prices with measures of the strength of zoning or land use restrictions. While CST find that on average in the U.S., a $\$ 1$ increase firm collateral resulting from an increase in local residential real estate prices leads to a $\$ 0.06$ increase in firm investment, with this simple extension we find that this increase is only around $\$ 0.04$ in states with the strongest zoning regulations while around $\$ 0.08$ in states with the weakest zoning regulations.

\footnotetext{
${ }^{3}$ This ranking of states by the strength of zoning and land-use restrictions is taken from the work of Daniel Shoag and co-authors (see e.g. Shoag and Muehlegger (2015), Ganong and Shoag (2017), and Shoag and Russell (2018)) and will be discussed in the next section.
} 
Second, we consider the model from LWZ, but instead of forcing residential and commercial real estate to be perfect substitutes, we allow the two types of land to be imperfect substitutes. With this model we can find reasonable values for the elasticity of substitution between residential and commercial real estate. In particular we find that the two types of real estate are not highly substitutable, and the elasticity of substitution between the two types of land is around 0.35 for the U.S. as a whole, and it can be as high as 0.66 in states with weak zoning regulations and as low as 0.16 in states with strong zoning regulations. Using these calibrated values of the elasticity of substitution between the two types of land, we examine how the strength of the collateral channel is affected by this imperfect land substitutability. We find that the collateral channel is much stronger when the elasticity of substitution between the different types of land is higher.

Gyourko (2009) compares commercial and residential real estate markets and argues that while there are important differences between the two, the behavior of prices is very similar in the two markets. Bouchouicha and Ftiti (2012) argue that there is a common trend that drives prices in both the residential and commercial real estate markets.

While in most (but not all) cases residential structures can't be converted to commercial structures and vice versa, the land beneath that structure certainly can be converted from residential to commercial use if the law allows. Davis and Heathcote (2007) decompose the value of the U.S. residential housing stock into the value of structures and the value of underlying land. They show that at the business cycle frequency, the value of the underlying land is 5 times more volatile than the value of the structure, and thus at the business cycle frequency the main driver of the value of a real estate holding is not the non-substitutable structure on top, but the (potentially) substitutable land underneath. Davis (2009) performs a similar exercise looking at the value of underlying land by use, and argues that the price of residential land generally performs very differently than the price of commercial land. Sirmans and Slade (2012) and Nichols et al. (2013) use transactions data to construct residential and commercial land price indices, and they show while the two exhibited many of 
the same properties during the run up of the housing bubble in the early 2000's, during the peak bubble years the two land prices began to diverge and residential land prices climbed to a higher peak and had a greater fall.

Supporting the conclusions of CST, other papers find similar evidence in the international data. Using data from Japanese firms, Gan (2007) finds that for every 10 percent drop in collateral value, the investment rate of an average firm is reduced by 0.8 percentage points, while Kleiner (2015) finds evidence of a similar channel in the UK, and Kaas et al. (2016) in France. Adelino et al. (2015) argue that this channel is very important for small business lending, and argue that in the US, local house price fluctuations lead to fluctuations in employment in small businesses that is not seen in large firms in the same area and industry. In a reduced form estimation Catherine et al. (2018) first find that a $\$ 1$ increase in real estate value leads to a significant $\$ 0.04$ increase in investment in the US. They then incorporate these results in a general equilibrium model to calculate the overall welfare loss from financing constraints. However, examining data from Chinese firms, Wu et al. (2013) do not find evidence of the same collateral channel from real estate to firm investment in China, and they argue that one reason for this is the fact that state-owned firms do not appear to rely on land collateral values to obtain financing.

The theoretical model section of the paper is an extension of the collateral channel model in LWZ. Other extensions to LWZ include Liu et al. (2016) who incorporate a labor search and matching framework into the same model to explain the observed negative correlation between land prices and unemployment and the fact that housing demand shocks have a large effect on unemployment volatility. Bahaj et al. (2016) allow entrepreneurs to use the residential housing owned by the entrepreneur as collateral or business investment, and Bahaj et al. (2020) show that among UK firms, a $£ 1$ increase in the home values of a firm's directors leads to a $£ 0.03$ increase in that firm's investment spending, although they find this effect only holds in smaller firms where the value of a director's personal property is 
sizable compared to the firm's assets. ${ }^{4}$ In another extension of the LWZ framework, Gong et al. (2017) alter the household utility function to allow for a substitutability between consumption and leisure. This reduces the labor supply elasticity and the amplification effect of the credit constraint triggered by the housing demand shock on key macroeconomic variables is greatly reduced.

This paper will proceed as follows. Section 2 presents a simple extension of the reduced form empirical model in CST to allow for cross-state heterogeneity in zoning and land-use regulations. The theoretical model is presented in Section 3. This is identical to the model in LWZ except the land market clearing condition is modified to allow the two types of land to be imperfect substitutes. The estimation of the model is described in Section 4 . The results about how the strength of the collateral channel depends on the substitutability of the two types of land is presented in Section 5. Finally, Section 6 concludes.

\section{Imperfect substitutability and the collateral channel}

In this section we present some empirical evidence of how cross-state heterogeneity in the strength of zoning regulations can affect the strength of the collateral channel that links increases in residential real estate prices to increases in firm investment. We begin by presenting some simple scatter plot regressions that show that cross-state heterogeneity in the strength of zoning regulations has an effect on cross-state heterogeneity in the correlation between residential and commercial real estate prices. We then discuss how the estimation strategy in CST can be extended to take account of cross-state heterogeneity in zoning and land-use regulations.

\footnotetext{
${ }^{4}$ Schmalz et al. (2017) compare the effect of local house price differences on entrepreneurial activity between home owners and renters and find additional evidence for this channel where entrepreneurs use their own houses as collateral for business loans.
} 


\subsection{Zoning Regulations and the Correlation between Commercial and Residential Real Estate Prices}

Residential and commercial real estate are not perfect substitutes. When the S\&P Case Shiller residential price series and the Federal Reserve Board's commercial real estate price index are both detrended by the core CPE deflator, the correlation between the two series over 1975:Q1 to 2010:Q4 is 0.64 .

This imperfect substitutability could be due to any number of factors. One potential candidate is zoning regulations which impose legal barriers to the conversion of a plot of land from residential to commercial use. At the city level, we collect data on commercial (industrial use) real estate prices from $\mathrm{CBRE}$ and residential real estate prices from the Federal Housing Administration. With the available data we can construct a balanced panel of these two series for 51 U.S. cities from 1994:Q1 to 2018:Q4. ${ }^{5}$ When both are detrended by the core CPE deflator, the cross-city mean correlation between commercial and residential real estate prices is 0.66 . The median is 0.73 and the 25 th and 75 th percentiles are 0.60 and 0.86 .

This considerable heterogeneity in correlation across U.S. cities can be compared to state level heterogeneity in zoning restrictions. U.S. states can be ranked 1 to 50 according to the strength of zoning or land-use regulations. Quantifying zoning regulations across cities is difficult, since many types of zoning or land-use regulations exist. To rank the states we use a data set from the work of Daniel Shoag and co-authors (e.g. Shoag and Muehlegger (2015), Ganong and Shoag (2017), and Shoag and Russell (2018)) which counts the number of state supreme or appellate court decisions that include the words "land use" or "zoning".

\footnotetext{
${ }^{5}$ The 51 cities are: Albuquerque, Atlanta, Austin, Baltimore, Boston, Charlotte, Chicago, Cincinnati, Cleveland, Columbus, Dallas, Denver, Detroit, Fort Lauderdale, Fort Worth, Hartford, Houston, Indianapolis, Jacksonville, Kansas City, Las Vegas, Los Angeles, Memphis, Miami, Minneapolis, Nashville, New York, Newark, Oakland, Orange County, Orlando, Philadelphia, Phoenix, Pittsburgh, Portland, Raleigh, Riverside, Sacramento, Salt Lake City, San Diego, San Francisco, San Jose, Seattle, St. Louis, Stamford, Tampa, Tucson, Vallejo, Ventura, West Palm Beach, Wilmington.
} 
While of course this measure is imperfect, it does capture the number of times zoning or land use cases appear in a state's courts, and thus is a reasonable proxy for the number and strength of zoning or land use regulations in that state. ${ }^{6}$

In a scatter plot we can plot the city level correlation between residential and commercial real estate against the state level zoning or land use regulations rank. These scatter plots are presented in Figure 1. The coefficient of the trend line in each scatter plot is about 0.008 , implying that as the state's zoning rank increases by 1 (meaning zoning or land use regulations become less restrictive) the correlation between residential and commercial real estate increases by about 0.008 , which is highly significant in both scatter plots. The intercept is around 0.40, and thus all else equal, a city in a state with the most restrictive zoning or land use regulations (Ohio) should have a correlation of around 0.40 and a city in a state with the least restrictive regulations (Oklahoma) should have a correlation of 0.80 . The $\mathrm{R}^{2}$ from each of these regressions indicates that cross-state heterogeneity in zoning or land use regulations explains about $20 \%$ of cross-city heterogeneity in the correlation between commercial and residential real estate. ${ }^{7}$

\subsection{Empirical Strategy}

First we briefly describe the estimation strategy in CST, and our modification to account for cross-state heterogeneity in zoning and land-use restrictions. Here we give a summary of the methodology and data used to produce the main results in CST, for more details and for robustness checks, we refer the reader to the original paper and their Additional Materials

\footnotetext{
${ }^{6}$ As shown by Ganong and Shoag (2017), the ordering of states from least restrictive to most restrictive using this measure based on court decisions is very similar to an ordering based on the land use survey results from Gyourko et al. (2008) and Gyourko et al. (2019).

${ }^{7}$ The cities with the lowest correlation are Cleveland, $\mathrm{OH}$ and Wilmington, $\mathrm{DE}$ at -0.16 and -0.18 . The city with the highest correlation is Houston, TX at 0.98 . Ohio is the most restrictive state for both zoning and land use regulations, and Deleware is the 3rd most restrictive state for land use and the 6th for zoning. Texas is the 49th most restrictive state for both, and Houston is the only major city in the U.S. without city zoning regulations.
} 
on the AER website.

CST collect data annual accounting data from U.S. listed firms over the years 1993-2007. They collect data from COMPUSTAT firms active in 1993 with non-missing total assets. They require that a firm in the sample has data for every consecutive year that they appear in the sample, and that the firm's data be available for 3 consecutive years. With this firm-level data they measure how changes in a firm's real state value affects firm investment:

$$
I N V_{i, t}=\alpha_{i}+\delta_{t}+\beta R E_{-} V_{a l, t}+\gamma P_{t}^{l}+\text { controls }_{i, t}+\varepsilon_{i, t}
$$

where $I N V_{i, t}$ is the ratio of investment to lagged PPE by firm $i$ in year $t, R E \_V a l_{i, t}$ is the ratio of the value of the firm's real estate holdings in year $t$ to lagged PPE, $P_{t}^{l}$ is local residential real estate prices in location $l$, whether the state or the MSA where firm $i$ is located. Controls include firm specific factors like ROA, total assets, firm age, 2-digit SIC dummies, and the state dummies all interacted with local real estate prices $P_{t}^{l}$. Since they are generally found to be significant predictors of firm level investment in the literature, CST also include a ratio of a firm's cash flow in year $t$ to lagged PPE and the market/book ratio in year $t$ as controls.

The value of a firm's real estate holdings can be estimated using COMPUSTAT data on a firm's property and the accumulated value of depreciation. With this balance sheet data CST can calculate the market value of a firm's property in the year it was purchased. Then in all subsequent years the market value at the time of purchase is inflated by the local residential real estate price index to approximate the current market value of a firm's property. In that way $R E E_{-} V a l_{i, t}$ is a scalar describing firm $i$ 's initial real estate holdings interacted with local real estate prices (and then all normalized by lagged PPE). ${ }^{8}$

\footnotetext{
${ }^{8}$ Specifically, the balance sheet reports the value of a firm's property at cost, not market value. CST use balance sheet data on accumulated depreciation to calculate the average age of a firm's real estate (assuming depreciable life of 40 years). The value of the firm's real estate at cost is the approximate market value in the year the property was acquired. This market value in the past is then inflated by the local real estate price index to approximate the current market value of a firm's property.
} 
Local real estate prices are given by the Home Price Index from the Office of Federal Housing Enterprise Oversight. This enters the regression both as a stand alone variable and as part of $R E_{-} V_{a l} l_{i, t}$ and is available at the state and the MSA level. We report the effects of both. CST also replace residential real estate prices with commercial real estate prices both as a stand-alone variable and as a component of $R E \_V a l_{i, t}$ in a few specifications. But in this paper we focus on the channel from residential house prices to firm collateral, so we use the regression specifications considering only residential real estate prices.

In mechanical terms, the estimated coefficient $\hat{\beta}$ measures the effect of an increase in local residential real estate prices on the investment rates of local land holding firms. This coefficient should be a reduced form combination of two factors. First, whether an increase in local residential real estate prices translates into an increase in firm collateral, and second, whether an increase in firm collateral leads to an increase in firm investment. CST address the second factor, and show that the link between collateral values and firm investment is stronger among firms that would be classified as credit constrained. Here we address the first of these factors, whether a change in local residential real estate prices translates into a change in the value of a firm's real estate collateral. This will depend on the substitutability of residential and commercial real estate, and thus whether a change in residential real estate prices is associated with a similar change in commercial real estate prices.

Thus we modify the original CST model to allow for cross-state heterogeneity in zoning or land use regulations. To the regression model in equation (1) we add the term $\operatorname{Rank}_{l} \times$ $R E \_V a l_{i, t}$, the interaction between $R E \_V a l_{i, t}$ and a state's rank in the strength of zoning or land use regulations, as presented earlier in Figure 1. This new interaction term has a coefficient of $\lambda$, and thus the effect of $R E_{-} V a l_{i, t}$ on firm investment in the state with the strongest zoning regulations (Ohio) is $\hat{\beta}+1 \times \hat{\lambda}$, while the effect of $R E \_V a l_{i, t}$ on firm investment in the state with the weakest zoning regulations (Oklahoma) is $\hat{\beta}+50 \times \hat{\lambda}$, where year to year changes in $R E_{-} V a l_{i, t}$ are proxied by year to year changes in the price of residential real estate. 


\section{$2.3 \quad$ Results}

The results from this replication and then modification of CST are presented in Table 1. The first two columns present the results from the regression specification in columns 3 and 4 of table 5 of CST. The first column presents the results where the market value of a firm's real estate, $R E_{-} V a l$, is approximated using the residential real estate index at the state level. The second column presents the results where the market value of a firm's real estate is approximated using the residential real estate index at the MSA level. The headline finding of CST, that a $\$ 1$ increase in the value of a firm's collateral leads to a $\$ 0.06$ increase in firm investment is shown in the coefficients of $R E_{-} V a l^{\text {State }}$ or $R E_{-} V a l^{M S A}$ in the first two columns. Columns 3 and 4 then modify the regression specification in columns 1 and 2 by adding $R E \_V a l$ interacted with the state's rank in the strength of zoning regulations, Rank $^{\text {Zone }}$. Columns 5 and 6 do the same except the state's rank in zoning regulations is replaced by the state's rank in land use regulations, Rank $k^{\text {Land }}$.

The results in columns 3 and 4 show that the estimated coefficient of the interaction term $R E \_V a l \times R a n k^{Z o n e}$ is positive and statistically significant. This implies that the same increase in local residential real estate prices has a greater effect on firm investment in a state with weaker zoning regulations. The estimated coefficient of $R E \_V a l$ falls to about 0.04 when the interaction term is included in the regression and the coefficient of the interaction term $R E \_V a l \times R a n k^{Z o n e}$ is .00065. This implies that while a $\$ 1$ increase in local residential real estate prices is associated with a $\$ 0.06$ increase in firm investment on average in the U.S., this increase is only $\$ 0.04$ in the state with the strongest zoning regulations and is as high as $\$ 0.075$ in the state with the weakest zoning regulations.

Columns 5 and 6 repeat the same exercise but use state rankings in land use regulation instead of state rankings in zoning regulations. The same results hold. 


\section{Model}

The economy consists of two agents: a representative household and a representative entrepreneur. Households are more patient than entrepreneurs, households save and entrepreneurs borrow while facing a collateral constraint that binds in equilibrium.

\subsection{The Representative Household}

The representative household maximizes:

$$
E \sum_{t=0}^{\infty} \beta^{t} A_{t}\left\{\log \left(C_{h, t}-\gamma_{h} C_{h, t-1}\right)+\varphi_{t} \log L_{h, t}-\psi_{t} N_{h, t}\right\}
$$

where $C_{h, t}$ is household consumption, $L_{h, t}$ is housing services, $N_{h, t}$ is the household's labor

input, $\beta$ is the subjective discount factor, $\gamma_{h}$ is the degree of household habit persistence, $A$ is a shock to the household's patience factor (intertemporal preference shock), $\varphi_{t}$ is a shock to household's taste for housing services (housing demand shock), $\psi_{t}$ is a shock to labor supply.

The three shocks, the preference shock, the housing demand shock, and the labor supply shock follow the processes:

$$
\begin{aligned}
A_{t} & =A_{t-1}\left(1+\lambda_{a t}\right) \\
\ln \lambda_{a, t} & =\left(1-\rho_{a}\right) \ln \bar{\lambda}_{a}+\rho_{a} \ln \lambda_{a, t-1}+\sigma_{a} \varepsilon_{a, t}
\end{aligned}
$$

where $\rho_{a} \in(-1,1)$ is the persistence parameter, $\sigma_{a}$ is the standard deviation of the innovation, $\varepsilon_{a, t}$ is an iid standard normal process.

$$
\ln \varphi_{t}=\left(1-\rho_{\varphi}\right) \ln \bar{\varphi}+\rho_{\varphi} \ln \varphi_{t-1}+\sigma_{\varphi} \varepsilon_{\varphi, t}
$$


where $\rho_{\varphi} \in(-1,1)$ is the persistence parameter, $\sigma_{\varphi}>0$ is the standard deviation of the innovation, $\varepsilon_{\varphi, t}$ is an iid standard normal process.

$$
\ln \psi_{t}=\left(1-\rho_{\psi}\right) \ln \bar{\psi}+\rho_{\psi} \ln \psi_{t-1}+\sigma_{\psi} \varepsilon_{\psi, t}
$$

where $\rho_{\psi} \in(-1,1)$ is the persistence parameter, $\sigma_{\psi}>0$ is the standard deviation of the innovation, $\varepsilon_{\psi, t}$ is an iid standard normal process.

The household's budget constraint is given by:

$$
C_{h, t}+q_{h, t}\left(L_{h, t}-L_{h, t-1}\right)+\frac{S_{t}}{R_{t}} \leq w_{t} N_{h, t}+S_{t-1}
$$

where $q_{h, t}$ is the relative price of residential land in consumption units, $S_{t}$ is the household's purchase in period t of the loanable bond that pays off one unit of consumption good in all states of nature in period $\mathrm{t}+1, R_{t}$ is the gross real interest rate, $w_{t}$ is the real wage.

\subsection{The Representative Entrepreneur}

The representative entrepreneur maximizes:

$$
E \sum_{t=0}^{\infty} \beta^{t}\left[\log \left(C_{e, t}-\gamma_{e} C_{e, t-1}\right)\right]
$$

where $C_{e, t}$ is entrepreneur consumption, and $\gamma_{e}$ is the entrepreneur habit persistence parameter.

The entrepreneur owns a firm which produces output $Y_{t}$ sold in a perfectly competitive market using the following production function:

$$
Y_{t}=Z_{t}\left[L_{e, t-1}^{\phi} K_{t-1}^{(1-\phi)}\right]^{\alpha} N_{e . t}^{(1-\alpha)}
$$

where $Z_{t}$ is total factor productivity, $K_{t-1}$ is the capital input, $N_{e . t}$ is the labor input, and 
$L_{e, t-1}$ is the land input.

Total factor productivity, $Z_{t}$, is composed of a permanent component $Z_{t}^{p}$ and a transitory component $\nu_{t}$ :

$$
Z_{t}=Z_{t}^{p} \nu_{z, t}
$$

where the permanent component follows:

$$
\begin{aligned}
Z_{t}^{p} & =Z_{t-1}^{p} \lambda_{z, t} \\
\ln \lambda_{z, t} & =\left(1-\rho_{z}\right) \ln \bar{\lambda}_{z}+\rho_{z} \ln \lambda_{z, t-1}+\sigma_{z} \varepsilon_{z, t}
\end{aligned}
$$

where $\bar{\lambda}_{z}$ is the steady state growth rate of $Z_{t}^{p}, \rho_{z} \in(-1,1)$ is the persistence parameter, $\sigma_{z}$ is the standard deviation of the innovation, $\varepsilon_{z, t}$ is an iid standard normal process. And the transitory component follows:

$$
\ln \nu_{z, t}=\rho_{\nu_{z}} \ln \nu_{z, t-1}+\sigma_{\nu_{z}} \varepsilon_{\nu_{z}, t}
$$

where $\rho_{\nu_{z}} \in(-1,1)$ is the persistence parameter, $\sigma_{\nu_{z}}$ is the standard deviation of the innovation, $\varepsilon_{\nu_{z}, t}$ is an iid standard normal process.

Physical capital is accumulated according to:

$$
K_{t}=(1-\delta) K_{t-1}+\left[1-\frac{\Omega}{2}\left(\frac{I_{t}}{I_{t-1}}-\bar{\lambda}_{I}\right)^{2}\right] I_{t}
$$

where $I_{t}$ is physical capital investment, $\bar{\lambda}_{I}$ is the steady state growth of investment, $\delta$ the capital depreciation parameter, and $\Omega>0$ is the adjustment cost parameter.

The entrepreneur's budget constraint is given by: 


$$
C_{e, t}+q_{e, t} e_{t}\left(L_{e, t}-L_{e, t-1}\right)+B_{t-1}=Z_{t}\left[L_{e, t-1}^{\phi} K_{t-1}^{(1-\phi)}\right]^{\alpha} N_{e . t}^{(1-\alpha)}-\frac{I_{t}}{Q_{t}}-w_{t} N_{e, t}+\frac{B_{t}}{R_{t}}
$$

where $q_{e, t}$ is the relative price of residential land in consumption units, and $B_{t}$ is the representative entrepreneur's debt. The shock $e_{t}$ is a commercial construction cost shock, and $Q_{t}$ is an investment-specific technology shock.

The construction cost shock $e_{t}$ is not in the original LWZ model. Since the two types of land are perfect substitutes, LWZ estimate the model with one price of land. In this model the two types of land are imperfect substitutes, and therefore we estimate the model with two real estate price series, a residential series and a commercial series. As we will see in the next subsection, this construction cost shock appears in the equilibrium condition linking the prices of the two types of land, and thus partly explains any difference between the two real estate price series. The construction cost shock $e_{t}$ follows:

$$
\ln e_{t}=\left(1-\rho_{e}\right) \ln \bar{e}+\rho_{e} \ln e_{t-1}+\sigma_{e} \epsilon_{e, t}
$$

where $\bar{e}$ is the steady state value of $e_{t}, \rho_{e} \in(0,1)$ is the persistence parameter, $\sigma_{e}$ is the standard deviation, and $\varepsilon_{e, t}$ is an iid standard normal process.

The investment-specific technology shock $Q_{t}$ is composed of a permanent component $Q_{t}^{p}$ and a transitory component $\nu_{q, t}$ :

$$
Q_{t}=Q_{t}^{p} \nu_{Q, t}
$$

where the permanent component follows: 


$$
\begin{aligned}
Q_{t}^{p} & =Q_{t-1}^{p} \lambda_{Q, t} \\
\ln \lambda_{Q, t} & =\left(1-\rho_{Q}\right) \ln \bar{\lambda}_{Q}+\rho_{Q} \ln \lambda_{Q, t-1}+\sigma_{Q} \varepsilon_{Q, t}
\end{aligned}
$$

where $\bar{\lambda}_{q}$ is the steady state growth rate of $Q_{t}^{p}, \rho_{Q} \in(-1,1)$ is the persistence parameter, $\sigma_{Q}$ is the standard deviation of the innovation, $\varepsilon_{Q, t}$ is an iid standard normal process. And the transitory component follows:

$$
\ln \nu_{Q, t}=\rho_{\nu_{Q}} \ln \nu_{Q, t-1}+\varepsilon_{\nu_{Q}, t}
$$

where $\rho_{\nu_{Q}} \in(-1,1)$ is the persistence parameter, $\sigma_{\nu_{Q}}$ is the standard deviation of the innovation, $\varepsilon_{\nu_{Q}, t}$ is an iid standard normal process.

The entrepreneur is subject to a collateral constraint that the total values of their debt cannot be larger than a fraction of the expected value of their land and physical capital assets:

$$
B_{t} \leq \theta_{t} E_{t}\left[q_{e, t+1} L_{e, t}+q_{k, t+1} K_{t}\right]
$$

where $q_{k, t+1}$ is the shadow price of capital in consumption units. Since the price of new capital is $\frac{1}{Q_{t}}$, Tobin's $q$ in the model is given by $q_{k, t} Q_{t}$ which is the ratio of the value of installed capital to the price of new capital.

If the entrepreneur fails to pay the debt, the creditor can seize the land and the accumulated capital. Since it is costly to liquidate the seized land and capital stock, the creditor can recoup up to a fraction $\theta_{t}$ of the total value of collateral assets, where:

$$
\ln \theta_{t}=\left(1-\rho_{\theta}\right) \ln \bar{\theta}+\rho_{\theta} \ln \theta_{t-1}+\sigma_{\theta} \varepsilon_{\theta, t}
$$


where $\bar{\theta}$ is the steady state value of $\theta_{t}, \rho_{\theta} \in(0,1)$ is the persistence parameter, $\sigma_{\theta}$ is the standard deviation, and $\varepsilon_{\theta, t}$ is an iid standard normal process.

\subsection{Market Clearing Conditions}

Output $Y_{t}$ can be used for household consumption, entrepreneur consumption, or physical capital investment:

$$
C_{h, t}+C_{e, t}+\frac{I_{t}}{Q_{t}}=Y_{t}
$$

The total labor supplied by households is equal to the total labor employed by firms:

$$
N_{e, t}=N_{h, t}
$$

The total savings of households is equal to the total debt of entrepreneurs;

$$
S_{t}=B_{t}
$$

The key feature of this model and how it differs from LWZ is the land market clearing condition. The total supply of land is the constant $\bar{L}$. The market clearing condition for land is given by the following:

$$
\left[\left(\frac{\bar{L}_{e}}{\bar{L}}\right)^{-\frac{1}{\lambda}}\left(L_{e, t}\right)^{\frac{1+\lambda}{\lambda}}+\left(\frac{\bar{L}_{h}}{\bar{L}}\right)^{-\frac{1}{\lambda}}\left(L_{h, t}\right)^{\frac{1+\lambda}{\lambda}}\right]^{\frac{\lambda}{1+\lambda}}=\bar{L}
$$

where $\bar{L}_{h}$ and $\bar{L}_{e}$ are the steady state levels of household and entrepreneur land, and $\lambda>0$ is the elasticity of substitution between the two types of land. This land market clearing condition is expressed graphically (where $\bar{L}=1$ ) in Figure 2. Equilibrium in the market for land occurs where the marginal rate of technical substitution between the two types of land is equal to the ratio of their prices: 


$$
\left(\frac{L_{h, t}}{\bar{L}_{h}}\right)^{\frac{1}{\lambda}} /\left(\frac{L_{e, t}}{\bar{L}_{e}}\right)^{\frac{1}{\lambda}}=\frac{q_{h, t}}{e_{t} q_{e, t}}
$$

After linearization this becomes (after substituting the linearization of the land market clearing condition $\left.\bar{L}_{e} \hat{L}_{e, t}=-\bar{L}_{h} \hat{L}_{h, t}\right)$ :

$$
\hat{q}_{h, t}-\hat{e}_{t}-\hat{q}_{e, t}=\frac{1}{\lambda} \frac{1}{\bar{L}_{e}} \hat{L}_{h, t}
$$

In the limit as $\lambda \rightarrow \infty$ the two types of land become perfect substitutes, and the land market clearing condition becomes $L_{e, t}+L_{h, t}=\bar{L}$ and the equilibrium condition becomes $q_{h, t}=e_{t} q_{e, t}$. In the limit as $\lambda \rightarrow 0$ the two types of land become perfect compliments and the land market clearing condition becomes $L_{e, t}=\bar{L}_{e}$ and $L_{h, t}=\bar{L}_{h}$.

Note that $\lambda<\infty$ slows down reallocation in the land market. In the linearized equilibrium condition in equation (25), when $\lambda$ is finite, then if $\hat{L}_{h, t}>0$ and the current allocation of land to households is higher than its steady state level, $\hat{q}_{h, t}>\hat{e}_{t}+\hat{q}_{e, t}$ and land for households is relatively more expensive. Following a shock like a housing demand shock this will slow the reallocation of land from entrepreneurs to households. The same linearized equilibrium conditions can also be derived assuming that the two types of land are perfect substitutes in the land market clearing condition, $\bar{L}_{e}+\bar{L}_{h}=\bar{L}$, but entrepreneurs face a quadratic adjustment cost for reallocating land from households to entrepreneurs. The model assuming perfect substitutability in the land market clearing condition but adding an adjustment cost is presented in the appendix.

A competitive equilibrium consists of sequence prices $\left\{w_{t}, q_{h, t}, q_{e, t}, R_{t}\right\}_{t=0}^{\infty}$ and allocations $\left\{C_{h, t}, C_{e, t}, I_{t}, N_{h, t}, N_{e, t}, L_{h, t}, L_{e, t}, S_{t}, B_{t}, K_{t}, Y_{t}\right\}_{t=0}^{\infty}$ such that taking prices as given, the allocations solve the optimizing problems for the households and entrepreneurs and all the markets clear. 


\section{Estimation}

The goal of this exercise is to understand the effects of varying the elasticity of substitution between residential and commercial real estate, $\lambda$, holding all else equal. We use five of the six U.S. time series for the period of 1975Q1-2010Q4 from LWZ in our estimation: the inverse of the quality-adjusted relative price of investment, real per capita consumption, real per capita investment (in consumption units), real per capita non-farm non-financial business debt, and per capita hours worked (as a fraction of total time endowment). LWZ also include a land price series to represent their one real estate price. Since residential and commercial real estate are imperfect substitutes in this model we replace the one land price from LWZ with a residential and a commercial real estate price series: the S\&P CoreLogic Case-Shiller US national home price index, and the Federal Reserve Board's commercial real estate price index.

The full list of model parameter values is presented in Table 2. We follow LWZ in splitting these parameters into three groups. The first are the parameters $\gamma_{h}, \gamma_{e}, \Omega, g_{\gamma}$, and $\bar{\lambda}_{q}$. These are the two habit persistence parameters, the investment adjustment cost parameter, the growth rate of per capita output, and the growth rate of per capita investment. As shown in the table, we estimate these parameters using the same priors as LWZ. The second set of parameters is the $\operatorname{AR}(1)$ shock process parameters $\rho_{i}$ and $\sigma_{i}$ for $i=\left\{a, z, \nu_{z}, Q, \nu_{Q}, \varphi, \psi, \theta, e\right\}$. The first eight shocks are from LWZ and we reestimate using their same priors. The last shock, the commercial construction cost shock $e_{t}$ is unique to this paper, but LWZ use the same set of priors for each of the first eight shocks, so we just use that prior again when estimating the parameters in the process for $e_{t}$.

Our model is identical to that of LWZ except for the imperfect substitutability of land in the land market clearing condition in equation (23) and the construction shock $e_{t}$ in the entrepreneur's budget constraint in equation (13). Therefore, our first step is to re-estimate this slightly modified model under different values of the elasticity parameter. We consider 
how the estimates of the model's parameters change as $\lambda$ goes from 100 (and thus the two types of land are nearly perfect substitutes, as in LWZ) to 0.01 (and thus the two types of land are nearly perfect compliments). Following LWZ, Table 2 shows the priors and the median posterior modes of our estimated parameters under different values of $\lambda$. We present the results from these estimations under different values of $\lambda$ in Figures 3, 4, and 5. In these figures, the posterior mode of each parameter as a function of the elasticity parameter $\lambda$ is plotted with the blue line. The median of these posterior modes is given by the green horizontal line. The figures also plot the posterior modes and $90 \%$ confidence intervals for the same parameters from LWZ with the red solid and dashed lines, respectively.

There are two important takeaways from these figures. First, despite some expected variability in values, in nearly all cases the median of the estimates under different levels of $\lambda$ is within the $90 \%$ confidence interval from LWZ. Second, there are no cases where a parameter estimate is monotonically increasing or decreasing in $\lambda$, thus we can feel confident that the values of these parameters are independent of $\lambda$.

One interesting example is in the estimates for $\rho_{e}$ and $\sigma_{e}$, the parameters of the shock process for our unique commercial housing construction shock. When $\lambda=100$, indicating that the two types of land are near perfect substitutes, there are extreme values for this shock process, since it alone explains any difference between the two land prices. But once we move away from the perfect substitutes assumption, the estimates for the process for the shock $e$ change, becoming less extreme, and is nearly constant as $\lambda$ changes.

In order to see the effect of varying the elasticity of substitution between the two types of real estate $\lambda$, holding all else equal, going forward we simply calibrate the model with the median value of the posterior modes for each of the estimated parameters (the green horizontal line in the figures), which are also listed in the first column of Table 2.

Finally the last set of parameters $\beta, \bar{\lambda}_{a}, \bar{\varphi}, \phi, \delta, \bar{e}, \alpha, \bar{\theta}$, and $\bar{\psi}$ are simply set to match certain steady state values. We fix the values of the last 4 of these: $\bar{e}=0.9$ is simply the ratio of the average of the residential real estate series to the average of the commercial real 
estate series, $\alpha=0.3$ to match a labor share of $70 \%, \bar{\theta}=0.75$ to match the average nonfarm and non-financial business loan-asset ratio, and the steady state value of the disutility of labor $\bar{\psi}$ is set so that steady state market hours are $25 \%$ of the time endowment. The values of the five parameters, $\beta, \bar{\lambda}_{a}, \bar{\varphi}, \phi$, and $\delta$, are set such that as the values of the earlier estimated parameters change, five steady state ratios and levels will hold: the steady state level of average real prime loan rate (4\% annually), the capital-output ratio (1.15 annually), investment-capital ratio (0.209 annually), the average ratio of commercial land to private output (0.65 annually), and the average ratio of residential land to private output (1.45 annually). What is shown in the table is the values of these five parameters that would make these five steady state ratios and levels hold when the estimated parameters in the model are equal to their "Median Mode" in the first column of Table 2.

\section{Results}

Using the parameter values listed in Table 2, we can then run simulations of the model under a range of values of $\lambda$ to see how changing the substitutability of residential and commercial land can affect the correlation between the prices of the two types of land. This correlation as a function of $\lambda$ taken from simulations of the model is presented in Figure 6 . The correlation falls monotonically as $\lambda$ goes from the near perfect substitutes case of $\lambda=100$, where the correlation is close to one, to the near perfect compliments case of $\lambda=0.01$, where the correlation is close to zero. The figure highlights three values of the correlation and their corresponding value of $\lambda$ from the model. The first is the correlation of 0.64 , as discussed in Section 2, this is the correlation between the S\&P Case Shiller residential price series and the Federal Reserve Board's commercial real estate price index, both detrended by the core CPE deflator, over the period 1975:Q1 to 2010:Q4. In the model, a correlation of 0.64 between the two series corresponds to $\lambda=0.35$. The other two values highlighted in the figure are 0.4 and 0.8. As discussed in Section 2, the scatter plot of the correlation between residential 
and commercial real estate price series at the MSA level against a state level ranking of zoning restrictions suggests that the states with the strongest zoning regulations should see a correlation between the two price series of 0.4 and the states with the weakest zoning regulations should see a correlation between the two price series of 0.8 . In the model, the correlations of 0.4 and 0.8 correspond to $\lambda=0.16$ and $\lambda=0.66$, respectively. Throughout the rest of this paper we use these three values: $\lambda=0.35, \lambda=0.16$, and $\lambda=0.66$ to represent the substitutability of residential and commercial land in the United States on average, in the states with the strongest zoning regulations, and in the states with the weakest zoning regulations.

The results from a forecast error variance decomposition are then presented in Figures 7 and 8. These figures plot the share of the forecast error variance of the commercial real estate, $q_{t}^{e}$, and investment, $I_{t}$, at the 24 quarter horizon that can be explained by each of the shocks in the model. Each figure plots how this variance decomposition changes as $\lambda$ changes. Figure 7 shows that when the two types of land are perfect substitutes, the housing demand shock explains $42 \%$ of the forecast error variance of the price of commercial real estate. As the two types of land become less substitutable, but when $\lambda=0.66$, the calibrated value for the states with the weakest zoning, the housing demand shock still explains nearly $9 \%$ of fluctuations in the commercial real estate price. However, when $\lambda=0.16$, the calibrated value for the states with the strongest zoning, the housing demand shock explains less than $1 \%$ of fluctuations in the commercial real estate price. As the share of the variance that can be explained by the housing demand shock falls, the share that can be explained by other shocks rise. Most notable is the collateral shock; when the two types of land are perfect substitutes, the collateral shock only explains $2 \%$ of the variance of the commercial real estate price, but when $\lambda=0.35$, the calibrated value for the U.S. data, that share increases to over $10 \%$.

Similarly, Figure 8 plots the effect of $\lambda$ on the variance decomposition of investment. The figure shows that when the two types of land are perfect substitutes the housing demand 
shock explains over $10 \%$ of the forecast error variance of investment, a direct indication of the strength of the collateral channel. But when $\lambda=0.35$, the housing demand shock explains less than $1 \%$ of the forecast error variance of investment. Similarly, when the two types of land are perfect substitutes, the collateral shock explains around $16 \%$ of the variance of investment, when $\lambda=0.35$ this share rises to $25 \%$.

Finally, the response of the residential land price $q_{t}^{h}$, the commercial land price $q_{t}^{e}$, and investment, $I_{t}$, to a one standard deviation shock to housing demand, $\varphi_{t}$, is presented in Figure 9. The impulse responses are plotted for 4 values of $\lambda$ : the near perfect substitutes case $\lambda=100$, the low zoning restrictions case $\lambda=0.66$, the average for the U.S. $\lambda=0.35$, and the high zoning restrictions case $\lambda=0.16$.

When the two types of land are nearly perfect substitutes, the housing demand shock leads to a nearly $1.5 \%$ increase in both land price series. In addition, it leads to a $3 \%$ increase in investment spending that is long-lived. A smaller value of $\lambda$ reduces the reallocation of land from commercial to residential use after the housing demand shock. With less reallocation, the supply curve for residential land is steeper and the same housing demand shock leads to a larger increase in the residential land price. At the same time, there is less pass through of the housing demand shock into commercial real estate prices. When $\lambda=0.66$, the calibrated value of $\lambda$ for light zoning states, the increase in investment spending is only $2 \%$ and it dissipates quickly. When $\lambda=0.16$, the calibrated value for states with tight zoning restrictions, the increase in investment spending following the same shock is less than $1 \%$.

\section{Conclusion}

This paper sets out to empirically test and then model how changes in the substitutability of residential and commercial real estate affects the transmission of a housing shock to the broader macroeconomy. An increase in residential real estate prices is associated with an increase in commercial real estate prices which should then lead to an increase in the 
value of collateral, borrowing, and investment spending for credit constrained firms. But the correlation between residential and commercial real estate prices, and thus the strength of this collateral channel linking housing demand and residential real estate prices to firm investment depends on the substitutability of the two types of land.

Using state level heterogeneity in the strength of zoning restrictions as a proxy for heterogeneity in the substitutability of the two types of real estate, this conjecture is confirmed with a reduced form empirical model using firm level data. We find that the estimated effect of an increase in local residential real estate prices on local firm investment spending is nearly twice as high in states with weak zoning regulations, where residential and commercial real estate are close substitutes. We then modify an earlier macroeconomic model of the collateral channel by adding the potential imperfect substitutability of the two types of real estate; we then model how increasing the substitutability of residential and commercial real estate can significantly strengthen the collateral channel that links housing demand and changes in residential real estate prices to investment spending. 


\section{References}

Adelino, M., Schoar, A., Severino, F., 2015. House prices, collateral, and self-employment. Journal of Financial Economics 117 (2), 288-306.

https://doi.org/10.1016/j.jfineco.2015.03.005

Bahaj, S., Foulis, A., Pinter, G., 2020. Home values and firm behavior. American Economic Review 110 (7), 2225-70.

https://www.aeaweb.org/articles?id=10.1257/aer. 20180649

Bahaj, S. A., Foulis, A., Pinter, G., 2016. The residential collateral channel. Working Paper.

Bouchouicha, R., Ftiti, Z., 2012. Real estate markets and the macroeconomy: A dynamic coherence framework. Economic Modelling 29 (5), 1820-1829.

https://doi.org/10.1016/j.econmod.2012.05.034

Catherine, S., Chaney, T., Huang, Z., Sraer, D. A., Thesmar, D., 2018. Quantifying reducedform evidence on collateral constraints. working paper.

http://dx.doi.org/10.2139/ssrn.2631055

Chaney, T., Sraer, D., Thesmar, D., 2012. The collateral channel: How real estate shocks affect corporate investment. American Economic Review 102 (6), 2381-2409.

http://doi.org/10.1257/aer.102.6.2381

Davis, M. A., 2009. The price and quantity of land by legal form of organization in the united states. Regional Science and Urban Economics 39 (3), 350-359.

https://doi.org/10.1016/j.regsciurbeco.2009.01.002

Davis, M. A., Heathcote, J., 2007. The price and quantity of residential land in the united states. Journal of Monetary Economics 54 (8), 2595-2620.

https://doi.org/10.1016/j.jmoneco.2007.06.023

Gan, J., 2007. Collateral, debt capacity, and corporate investment: Evidence from a natural experiment. Journal of Financial Economics 85 (3), 709-734.

https://doi.org/10.1016/j.jfineco.2006.06.007

Ganong, P., Shoag, D., 2017. Why has regional income convergence in the us declined? Journal of Urban Economics 102, 76-90.

https://doi.org/10.1016/j.jue.2017.07.002

Gong, L., Wang, C., Zhao, F., Zou, H.-f., 2017. Land-price dynamics and macroeconomic fluctuations with nonseparable preferences. Journal of Economic Dynamics and Control 83, 149-161.

https://doi.org/10.1016/j.jedc.2017.07.008 
Guerrieri, L., Iacoviello, M., 2017. Collateral constraints and macroeconomic asymmetries. Journal of Monetary Economics 90, 28-49.

https://doi.org/10.1016/j.jmoneco.2017.06.004

Gyourko, J., 2009. Understanding commercial real estate: How different from housing is it? The Journal of Portfolio Management 35 (5), 23-37.

https://doi.org/10.3905/JPM. 2009.35.5.023

Gyourko, J., Hartley, J., Krimmel, J., 2019. The local residential land use regulatory environment across us housing markets: Evidence from a new wharton index. NBER Working Paper No. 26573.

https://doi.org/10.3386/w26573

Gyourko, J., Saiz, A., Summers, A., 2008. A new measure of the local regulatory environment for housing markets: The wharton residential land use regulatory index. Urban Studies 45 (3), 693-729.

https://doi.org/10.1177/0042098007087341

Iacoviello, M., Neri, S., 2010. Housing market spillovers: evidence from an estimated dsge model. American Economic Journal: Macroeconomics 2 (2), 125-64.

https://doi.org/10.1257/mac.2.2.125

Kaas, L., Pintus, P. A., Ray, S., 2016. Land collateral and labor market dynamics in france. European Economic Review 84, 202-218. https://doi.org/10.1016/j. euroecorev.2014.11.002

Kleiner, K., 2015. Collateral and small firm labor. Kelley School of Business Research Paper (16-49).

http://dx.doi.org/10.2139/ssrn. 2704069

Liu, Z., Miao, J., Zha, T., 2016. Land prices and unemployment. Journal of Monetary Economics 80, 86-105. https://doi.org/10.1016/j.jmoneco.2016.05.001

Liu, Z., Wang, P., Zha, T., 2013. Land price dynamics and macroeconomic fluctuations. Econometrica 81 (3), 1147-1184. https://doi .org/10.3982/ECTA8994

Liu, Z., Wang, P., Zha, T., 2019. A theory of housing demand shocks. NBER Working Paper No. 25667. https://doi.org/10.3386/w25667 
Nichols, J. B., Oliner, S. D., Mulhall, M. R., 2013. Swings in commercial and residential land prices in the united states. Journal of Urban Economics 73 (1), 57-76.

https://doi.org/10.1016/j.jue.2012.06.004

Schmalz, M. C., Sraer, D. A., Thesmar, D., 2017. Housing collateral and entrepreneurship. The Journal of Finance 72 (1), 99-132. https://doi.org/10.1111/jofi.12468

Shoag, D., Muehlegger, E., 2015. Commuting times and land use regulations. Procedia Engineering 107, 488-493.

https://doi.org/10.1016/j.proeng.2015.06.108

Shoag, D., Russell, L., 2018. Land use regulations and fertility rates. In: One Hundred Years of Zoning and the Future of Cities. pp. 139-149.

https://doi .org/10.1007/978-3-319-66869-7-7

Sirmans, C., Slade, B. A., 2012. National transaction-based land price indices. The Journal of Real Estate Finance and Economics 45 (4), 829-845.

https://doi.org/10.1007/s11146-011-9306-3

Wu, J., Gyourko, J., Deng, Y., 2013. Is there evidence of a real estate collateral channel effect on listed firm investment in china? NBER Working Paper No. 18762.

https://doi.org/10.3386/w18762 


\section{A Appendix - For online publication}

\section{A.1 Model equations}

\section{A.1.1 Representative household}

The maximization problem for the representative household is:

$$
\begin{aligned}
\mathcal{L} & =\beta^{t} A_{t}\left\{\log \left(C_{h, t}-\gamma_{h} C_{h, t-1}\right)+\varphi_{t} \log L_{h, t}-\psi_{t} N_{h, t}\right\} \\
& +\mu_{h, t}\left(w_{t} N_{h, t}+S_{t-1}-C_{h, t}-q_{h, t}\left(L_{h, t}-L_{h, t-1}\right)-\frac{S_{t}}{R_{t}}\right)
\end{aligned}
$$

The first order conditions with respect to $C_{h, t}, L_{h, t}, N_{h, t}$, and $S_{t}$ are: wrt $C_{h, t}$ :

$$
A_{t}\left(\frac{1}{C_{h, t}-\gamma_{h} C_{h, t-1}}-E_{t}\left(1+\lambda_{a, t+1}\right) \frac{\beta \gamma_{h}}{C_{h, t+1}-\gamma_{h} C_{h, t}}\right)=\mu_{h, t}
$$

This FOC equates marginal utility of income and consumption. wrt $L_{h, t}$ :

$$
\beta E_{t} \frac{\mu_{h, t+1}}{\mu_{h, t}} q_{h, t+1}+\frac{A_{t} \varphi_{t}}{\mu_{h, t} L_{h, t}}=q_{h, t}
$$

This FOC equates the current relative price of land to the marginal benefit of purchasing an extra unit of land, which consists of the current utility benefits (MRS between housing and consumption) and the land's discounted future resale value.

wrt $N_{h, t}$ : 


$$
w_{t}=\frac{A_{t} \psi_{t}}{\mu_{h, t}}
$$

This FOC equates the real wage and the marginal rate of substitution between leisure and income.

wrt $S_{t}$ :

$$
\frac{1}{R_{t}}=\beta E_{t} \frac{\mu_{h, t+1}}{\mu_{h, t}}
$$

This FOC is the standard Euler equation for the loanable bond.

\section{A.1.2 Representative entrepreneur}

The maximization problem for the representative entrepreneur is:

$$
\begin{aligned}
\mathcal{L} & =\beta^{t}\left[\log \left(C_{e, t}-\gamma_{e} C_{e, t-1}\right)\right] \\
& +\mu_{e, t}\left(Z_{t}\left[L_{e, t-1}^{\phi} K_{t-1}^{(1-\phi)}\right]^{\alpha} N_{e . t}^{(1-\alpha)}+\frac{B_{t}}{R_{t}}-\frac{I_{t}}{Q_{t}}-w_{t} N_{e, t}-C_{e, t}-q_{e, t} e_{t}\left(L_{e, t}-L_{e, t-1}\right)-B_{t-1}\right) \\
& +\mu_{k, t}\left((1-\delta) K_{t-1}+\left[1-\frac{\Omega}{2}\left(\frac{I_{t}}{I_{t-1}}-\bar{\lambda}_{I}\right)^{2}\right] I_{t}-K_{t}\right) \\
& +\mu_{b, t}\left(\theta_{t} E_{t}\left[q_{e, t+1} L_{e, t}+q_{k, t+1} K_{t}\right]-B_{t}\right)
\end{aligned}
$$

The first order conditions with respect to $C_{e, t}, N_{e, t}, I_{t}, L_{e, t}, K_{t}, B_{t}$, are: wrt $C_{e, t}$ :

$$
\mu_{e, t}=\frac{1}{C_{e, t}-\gamma_{e} C_{e, t-1}}-E_{t} \frac{\beta \gamma_{e}}{C_{e, t+1}-\gamma_{e} C_{e, t}}
$$


wrt $N_{e, t}$ :

$$
w_{t}=\frac{(1-\alpha) Y_{t}}{N_{e, t}}
$$

wrt $I_{t}$ :

Define shadow price of capital in consumption units:

$$
\begin{gathered}
q_{k, t}=\frac{\mu_{k, t}}{\mu_{e, t}} \\
\frac{1}{Q_{t}}=q_{k, t}\left[1-\frac{\Omega}{2}\left(\frac{I_{t}}{I_{t-1}}-\bar{\lambda}_{I}\right)^{2}-\Omega\left(\frac{I_{t}}{I_{t-1}}-\bar{\lambda}_{I}\right)\left(\frac{I_{t}}{I_{t-1}}\right)\right] \\
+E_{t} q_{k, t+1} \frac{\mu_{e, t+1}}{\mu_{e, t}} \beta \Omega\left(\frac{I_{t+1}}{I_{t}}-\bar{\lambda}_{I}\right)\left(\frac{I_{t+1}}{I_{t}}\right)^{2}
\end{gathered}
$$

wrt $L_{e, t}$ :

$$
\frac{\mu_{e, t+1}}{\mu_{e, t}} \beta \alpha \phi \frac{Y_{t+1}}{L_{e, t}}+\frac{\mu_{b, t}}{\mu_{e, t}} \theta_{t} q_{e, t+1}+\frac{\mu_{e, t+1}}{\mu_{e, t}} \beta e_{t+1} q_{h, t+1}=q_{h, t} e_{t}+\chi q_{h, t}\left(L_{e, t}-\bar{L}_{e}\right)
$$

wrt $K_{t}$ :

$$
\beta E_{t} \frac{\mu_{e, t+1}}{\mu_{e, t}}\left(\frac{\alpha(1-\phi) Y_{t+1}}{K_{t}}+q_{k, t+1}(1-\delta)\right)+\frac{\mu_{b, t}}{\mu_{e, t}} \theta_{t} E_{t} q_{k, t+1}=q_{k, t}
$$

wrt $B_{t}$ :

$$
\frac{1}{R_{t}}=\beta E \frac{\mu_{e, t+1}}{\mu_{e, t}}+\frac{\mu_{b, t}}{\mu_{e, t}}
$$




\section{A.2 Adjustment cost instead of a CES for Land Market Clearing}

In the main text of the paper we treat residential and commercial land as imperfect substitutes, and the land market clearing equation is a CES with elasticity of substitution $\lambda$. Alternatively we could assume that the two types of land are perfect substitutes, but agents face a quadratic adjustment cost for converting real estate from one use to another:

$$
L_{h, t}+L_{e, t}+\frac{\chi}{2}\left(\frac{L_{e, t}}{\bar{L}_{e}}-1\right)^{2}=\bar{L}
$$

where $\chi$ is the adjustment cost parameter. Given this adjustment cost, one new unit of

commercial real estate will require converting $1+\chi\left(\frac{L_{e, t}}{L_{e}}-1\right)$ of residential real estate, and thus the equilibrium condition that connects the two real estate prices is:

$$
q_{h, t}\left(1+\chi\left(\frac{L_{e, t}}{\bar{L}_{e}}-1\right)\right)=e_{t} q_{e, t}
$$

After linearizing this is:

$$
\hat{q}_{h, t}+\chi\left(\hat{L}_{e, t}\right)=\hat{e}_{t}+\hat{q}_{e, t}
$$

And since the linearized land market clearing is $\bar{L}_{e} \hat{L}_{e, t}=-\bar{L}_{h} \hat{L}_{h, t}$, this becomes:

$$
\hat{q}_{h, t}-\hat{e}_{t}-\hat{q}_{e, t}=\chi\left(\frac{\bar{L}_{h}}{\bar{L}_{e}} \hat{L}_{h, t}\right)
$$

which is identical to the land market equilibrium condition in the text where $\lambda=\frac{1}{\chi \bar{L}_{h}}$. 
Figure 1: Scatter plots of the city-level correlation between residential and commercial (industrial) real estate against state rank in zoning or land use regulations.

Figure 2: The land market clearing condition

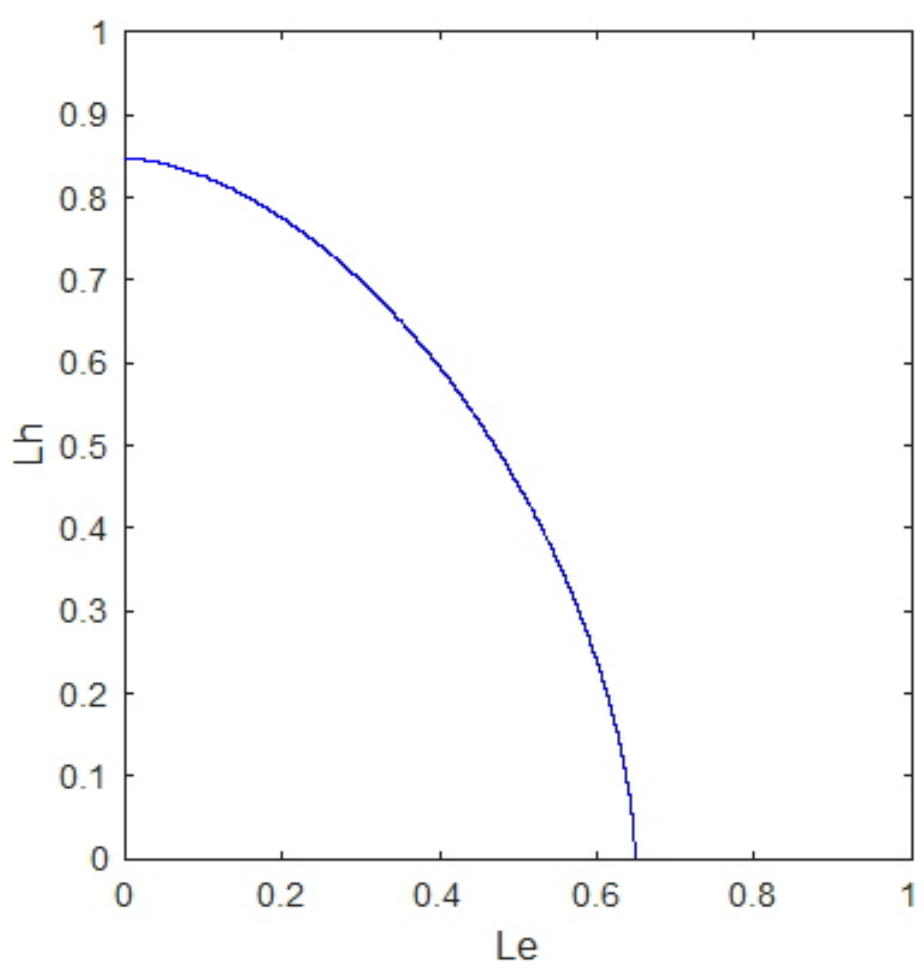


Figure 3: The estimated mode of the parameters in the model when estimated under different calibrated values of the elasticity of substitution between the two types of land.


Notes: The blue solid line are the estimates of the mode of the parameter in different estimations of the model when changing the $\lambda$ parameter. The green horizontal line is the median of those estimates. The red solid and dashed lines are thæ3modal estimate and $90 \%$ confidence bands for the parameter from Liu, Wang, and Zha (2013). 
Figure 4: The estimated mode of the parameters in the model when estimated under different calibrated values of the elasticity of substitution between the two types of land.


Notes: The blue solid line are the estimates of the mode of the parameter in different estimations of the model when changing the $\lambda$ parameter. The green horizontal line is the median of those estimates. The red solid and dashed lines are tḩ4modal estimate and $90 \%$ confidence bands for the parameter from Liu, Wang, and Zha (2013). 
Figure 5: The estimated mode of the parameters in the model when estimated under different calibrated values of the elasticity of substitution between the two types of land.
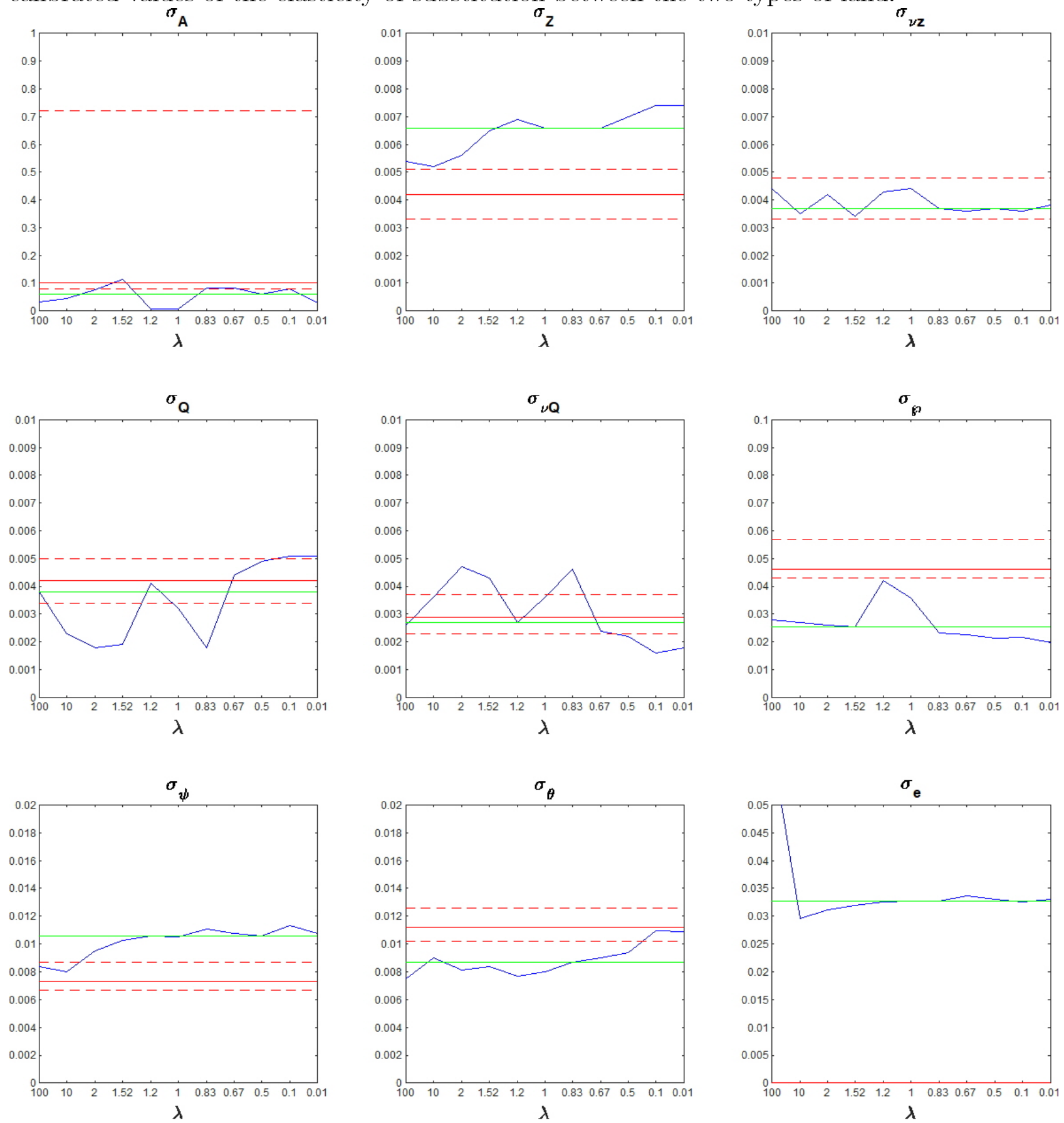

Notes: The blue solid line are the estimates of the mode of the parameter in different estimations of the model when changing the $\lambda$ parameter. The green horizontal line is the median of those estimates. The red solid and dashed lines are tḩ5modal estimate and $90 \%$ confidence bands for the parameter from Liu, Wang, and Zha (2013). 
Figure 6: The correlation between residential and commercial land prices as a function of the elasticity of substitution between the two types of land.

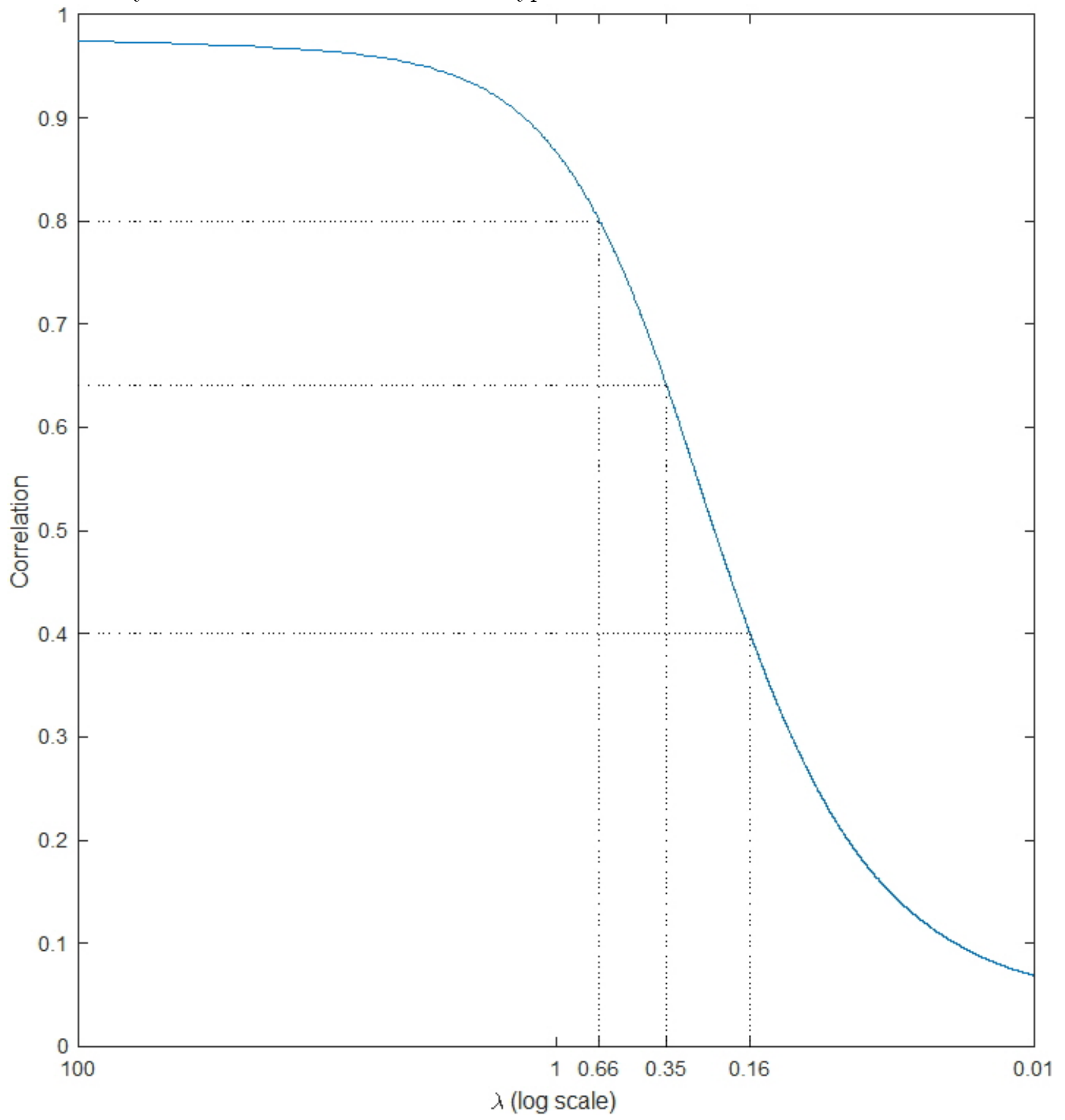


Figure 7: The share of the forecast error variance of the commercial real estate price at the 24 quarter horizon that is explained the each shock.
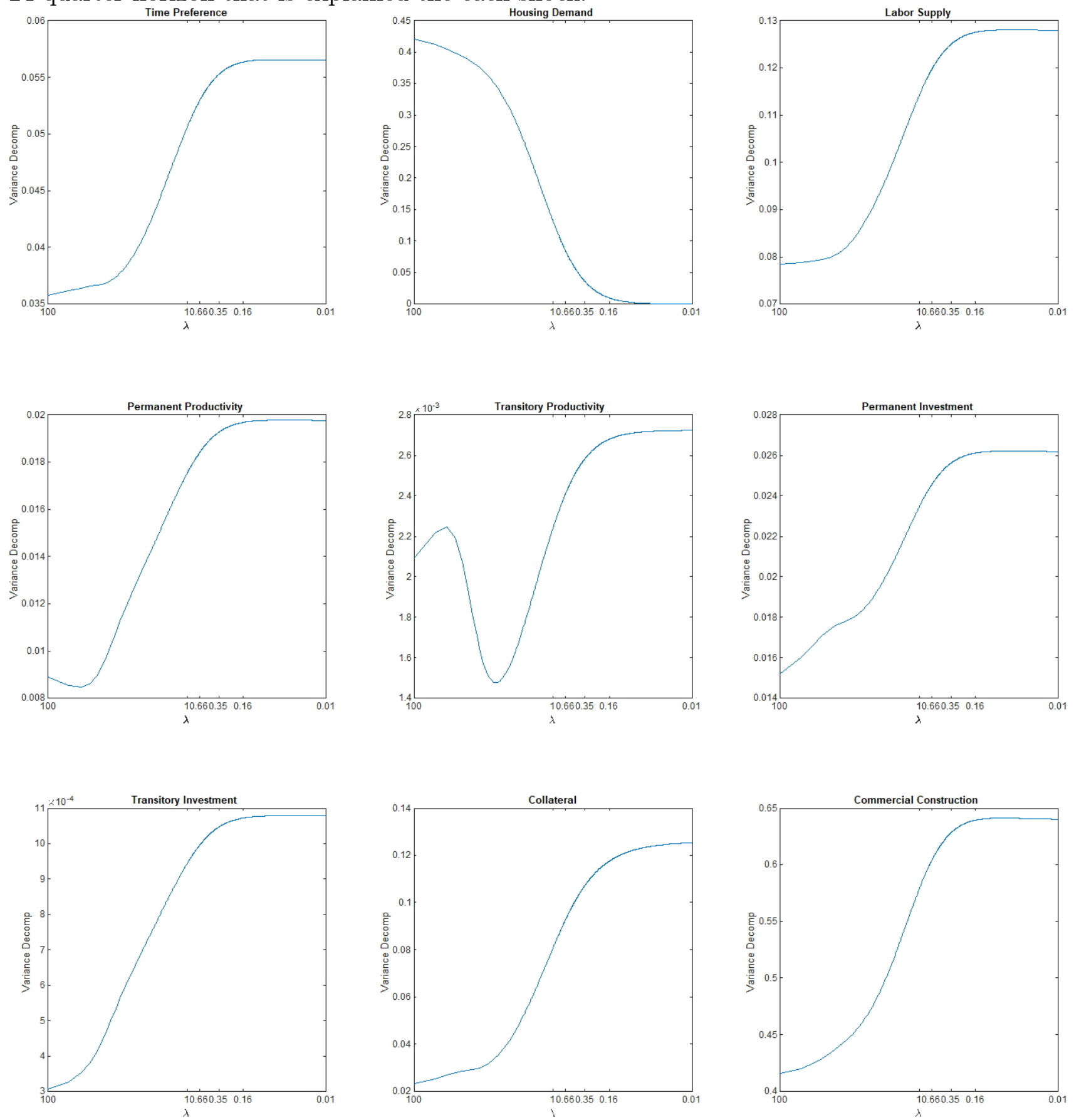
Figure 8: The share of the forecast error variance of investment at the 24 quarter horizon that is explained the each shock.
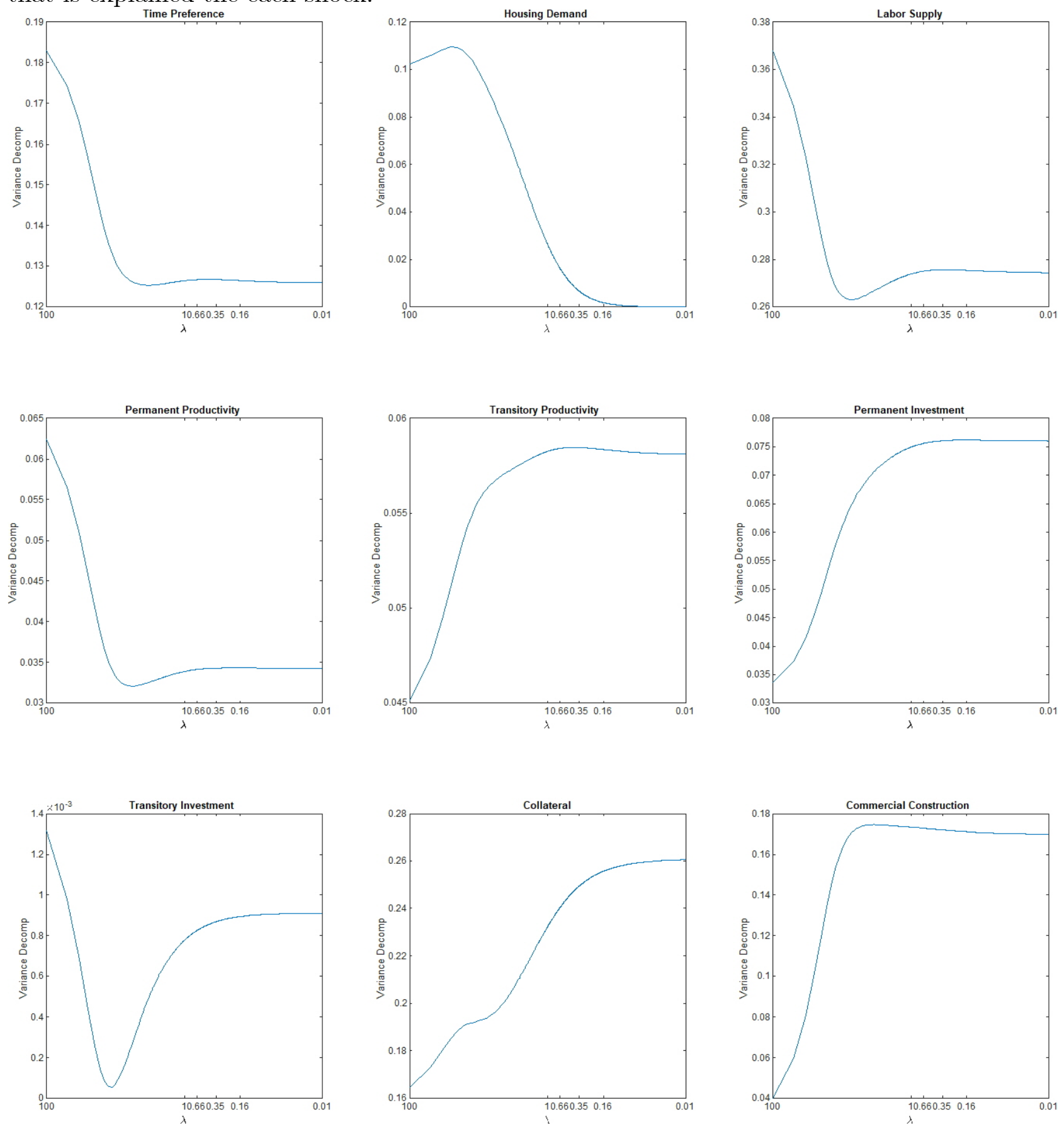
Figure 9: Impulse responses of the residential land price, the commercial land price, and investment under different values of the elasticity of substitution between the two types of land.
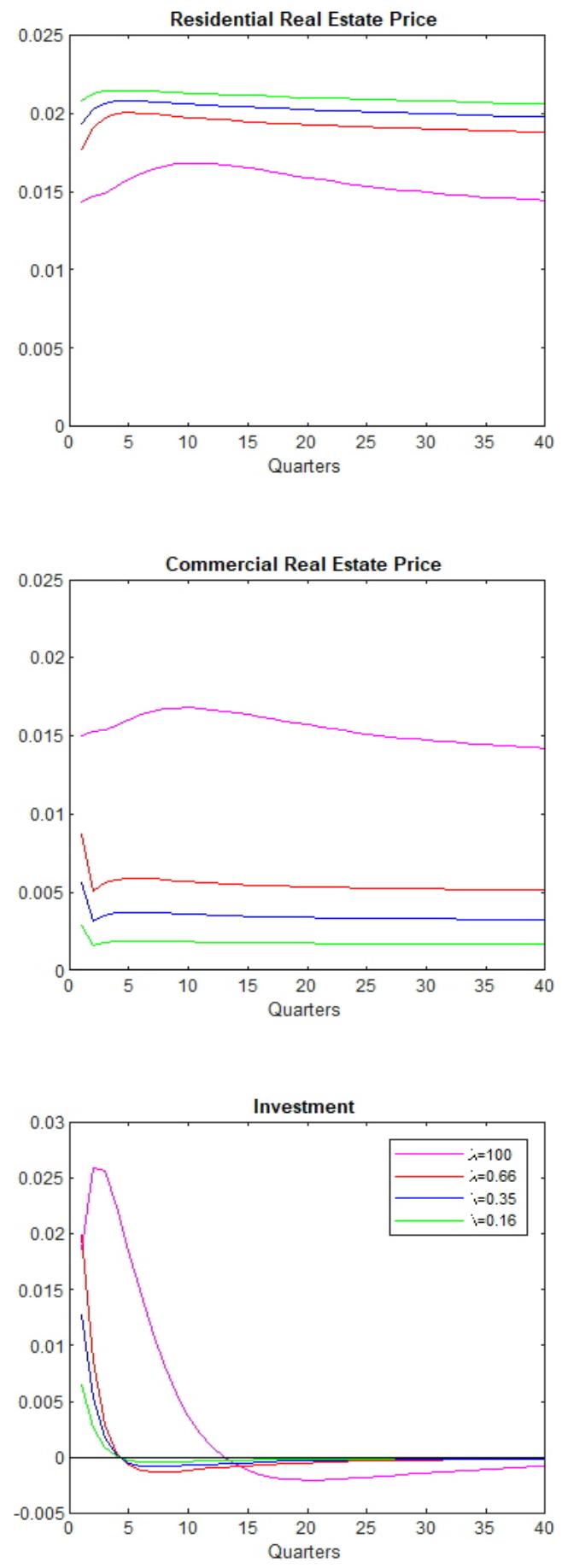
Table 1: The effect of firm real estate value on firm investment

\begin{tabular}{|c|c|c|c|c|c|c|}
\hline & \multicolumn{6}{|c|}{ Dependent Variable: $I N V$} \\
\hline & (1) & $(2)$ & (3) & $(4)$ & $(5)$ & (6) \\
\hline \multirow[t]{2}{*}{$R E_{-}$Val ${ }^{\text {State }}$} & $0.0584^{* * *}$ & & $0.0406^{* * *}$ & & $0.0379^{* * *}$ & \\
\hline & $(11.56)$ & & $(4.07)$ & & $(4.00)$ & \\
\hline \multirow[t]{2}{*}{$P^{\text {State }}$} & -0.218 & & -0.257 & & -0.225 & \\
\hline & $(-1.04)$ & & $(-1.22)$ & & $(-1.07)$ & \\
\hline \multirow[t]{2}{*}{$R E_{-} V a l^{M S A}$} & & $0.0581^{* * *}$ & & $0.0396^{* * *}$ & & $0.0358^{* * *}$ \\
\hline & & $(11.56)$ & & $(4.02)$ & & $(3.90)$ \\
\hline \multirow[t]{2}{*}{$P^{M S A}$} & & $-0.00226^{* *}$ & & $-0.00239^{* * *}$ & & $-0.00223^{* *}$ \\
\hline & & $(-2.51)$ & & $(-2.64)$ & & $(-2.47)$ \\
\hline \multirow[t]{2}{*}{$R E_{-}$Val $\times R_{a n k} k^{Z o n e}$} & & & $0.000649^{* *}$ & $0.000675^{* *}$ & & \\
\hline & & & $(2.07)$ & $(2.16)$ & & \\
\hline \multirow[t]{2}{*}{$R E_{-}$Val $\times R_{a n k} k^{L a n d}$} & & & & & $0.000729^{* *}$ & $0.000795^{* * *}$ \\
\hline & & & & & $(2.49)$ & $(2.72)$ \\
\hline \multirow[t]{2}{*}{ Cash } & $0.0230^{* * *}$ & $0.0230^{* * *}$ & $0.0230^{* * *}$ & $0.0229^{* * *}$ & $0.0230^{* * *}$ & $0.0230^{* * *}$ \\
\hline & $(8.26)$ & $(8.34)$ & $(8.25)$ & $(8.33)$ & $(8.27)$ & $(8.34)$ \\
\hline \multirow[t]{2}{*}{ Market/book } & $0.0637^{* * *}$ & $0.0638^{* * *}$ & $0.0636^{* * *}$ & $0.0638^{* * *}$ & $0.0637^{* * *}$ & $0.0638^{* * *}$ \\
\hline & $(19.66)$ & $(20.95)$ & $(19.64)$ & $(20.93)$ & $(19.63)$ & $(20.94)$ \\
\hline Controls $\times P^{\text {State }}$ & Yes & No & Yes & No & Yes & No \\
\hline Controls $\times P^{M S A}$ & No & Yes & No & Yes & No & Yes \\
\hline Firm Fixed Effects & Yes & Yes & Yes & Yes & Yes & Yes \\
\hline Year Fixed Effects & Yes & Yes & Yes & Yes & Yes & Yes \\
\hline Obs. & 25902 & 25726 & 25902 & 25726 & 25902 & 25726 \\
\hline $\bar{R}^{2}$ & 0.309 & 0.309 & 0.309 & 0.309 & 0.309 & 0.309 \\
\hline
\end{tabular}

Notes: $* * * / * * *$ denote $1 / 5 / 10 \%$ significance levels. This table reports the empirical link between the value of a firm's real estate assets and firm investment. The dependent variable is firm investment normalized by lagged PPE. Columns 1, 3, and 5 use state level residential real estate prices as a proxy for the market value of a firm's real estate assets, Columns 2,4, and 6 proxy instead by MSA level residential real estate prices. All regressions control for firm-level initial characteristics (five quintiles of age, asset, and ROA, as well as two-digit industry and state of location) interacted with Real Estate Prices. All regressions, control for Cash and previous year Market/Book. All specifications use year and firm fixed effects and cluster observations at the state-year or MSA-year level. T-stats are in parentheses. 
Table 2: Prior and Posterior Distribution of Parameters.

\begin{tabular}{|c|c|c|c|c|c|c|}
\hline \multicolumn{7}{|c|}{ Estimated Parameters: } \\
\hline & Median Mode & Prior Distribution & $\mathrm{a}$ & $\mathrm{b}$ & Prior Mean & Prior St. Dev. \\
\hline$\gamma_{h}$ & 0.554 & $\operatorname{Beta}(a, b)$ & 1.000 & 2.000 & 0.333 & 0.236 \\
\hline$\gamma_{e}$ & 0.590 & $\operatorname{Beta}(a, b)$ & 1.000 & 2.000 & 0.333 & 0.236 \\
\hline$\Omega$ & 0.175 & $\operatorname{Gamma}(a, b)$ & 1.000 & 0.500 & 2.000 & 2.000 \\
\hline $100\left(g_{\gamma}-1\right)$ & 0.524 & $\operatorname{Gamma}(a, b)$ & 1.861 & 3.012 & 0.618 & 0.453 \\
\hline $100\left(\bar{\lambda}_{q}-1\right)$ & 1.352 & $\operatorname{Gamma(a,b)}$ & 1.861 & 3.012 & 0.618 & 0.453 \\
\hline$\rho_{a}$ & 0.892 & $\operatorname{Beta}(a, b)$ & 1.000 & 2.000 & 0.333 & 0.236 \\
\hline$\rho_{z}$ & 0.379 & $\operatorname{Beta}(a, b)$ & 1.000 & 2.000 & 0.333 & 0.236 \\
\hline$\rho_{\nu_{z}}$ & 0.035 & $\operatorname{Beta}(a, b)$ & 1.000 & 2.000 & 0.333 & 0.236 \\
\hline$\rho_{Q}$ & 0.546 & $\operatorname{Beta}(a, b)$ & 1.000 & 2.000 & 0.333 & 0.236 \\
\hline$\rho_{\nu Q}$ & 0.413 & $\operatorname{Beta}(a, b)$ & 1.000 & 2.000 & 0.333 & 0.236 \\
\hline$\rho_{\varphi}$ & 0.999 & $\operatorname{Beta}(a, b)$ & 1.000 & 2.000 & 0.333 & 0.236 \\
\hline$\rho_{\psi}$ & 0.946 & $\operatorname{Beta}(a, b)$ & 1.000 & 2.000 & 0.333 & 0.236 \\
\hline$\rho_{\theta}$ & 0.993 & $\operatorname{Beta}(a, b)$ & 1.000 & 2.000 & 0.333 & 0.236 \\
\hline$\rho_{e}$ & 0.894 & $\operatorname{Beta}(a, b)$ & 1.000 & 2.000 & 0.333 & 0.236 \\
\hline$\sigma_{a}$ & 0.077 & Inv Gamma(a,b) & 0.326 & $1.45 E-04$ & 0.01 & $\operatorname{Inf}$ \\
\hline$\sigma_{z}$ & 0.007 & $\operatorname{Inv} \operatorname{Gamma}(a, b)$ & 0.326 & $1.45 E-04$ & 0.01 & $\operatorname{Inf}$ \\
\hline$\sigma_{\nu_{z}}$ & 0.004 & $\operatorname{Inv} \operatorname{Gamma}(a, b)$ & 0.326 & $1.45 E-04$ & 0.01 & $\operatorname{Inf}$ \\
\hline$\sigma_{q}$ & 0.004 & $\operatorname{Inv} \operatorname{Gamma}(a, b)$ & 0.326 & $1.45 E-04$ & 0.01 & $\operatorname{Inf}$ \\
\hline$\sigma_{\nu_{q}}$ & 0.003 & Inv Gamma(a,b) & 0.326 & $1.45 E-04$ & 0.01 & $\operatorname{Inf}$ \\
\hline$\sigma_{\varphi}$ & 0.027 & $\operatorname{Inv} \operatorname{Gamma}(a, b)$ & 0.326 & $1.45 E-04$ & 0.01 & $\operatorname{Inf}$ \\
\hline$\sigma_{\psi}$ & 0.010 & $\operatorname{Inv} \operatorname{Gamma}(a, b)$ & 0.326 & $1.45 E-04$ & 0.01 & $\operatorname{Inf}$ \\
\hline$\sigma_{\theta}$ & 0.009 & $\operatorname{Inv} \operatorname{Gamma}(a, b)$ & 0.326 & $1.45 E-04$ & 0.01 & $\operatorname{Inf}$ \\
\hline$\sigma_{e}$ & 0.033 & $\operatorname{Inv} \operatorname{Gamma}(a, b)$ & 0.326 & $1.45 E-04$ & 0.01 & $\operatorname{Inf}$ \\
\hline \multicolumn{7}{|c|}{ Simulated Parameters: } \\
\hline$\beta$ & 0.982 & & & & & \\
\hline $\bar{\lambda}_{a}$ & 0.014 & & & & & \\
\hline $\bar{\varphi}$ & 0.026 & & & & & \\
\hline$\phi$ & 0.049 & & & & & \\
\hline$\delta$ & 0.035 & & & & & \\
\hline
\end{tabular}

Notes: The median mode is the median of the posterior mode of the parameter across estimations where the $\lambda$ parameter is calibrated to be $0.01,0.1,0.5,0.66,0.83,1,1.2,1.5,2,10$, and 100 